\title{
خلخال من الفضة مطعم بالمينا الملونة محفوظ بمتحف جاير أندرسون لم يسبق نشره
}

ـ أ.د / شادية الاسوقى عبد العزيز كثك 1 ـ الباحثة / شهر ماهر فؤاد محمود حمدى2 2

ملخص البحث يسبق نشره ودر استه من قبل محفوظ بمتحف جاير أندرسون ، و أعتمد المنهج العلمى للدر اسة على الوصف و التحليل و المقارنة وقد بينت الدراسة أساليب الصناعة وطرق التشكيل و الزخرفة المختلفة

للخلخال . لال

\section{Abstract}

الكلمات الادالة : الحُلى ـ تركيا ـ- الفنون - الخلاخيل

This study is concerned in studying archaeological and artistic of a piece of anklet jewelry , which date back to the $13^{\text {th }}$ century AH 19 AD .It was not previously publishedand studied by preserved in the Gayer Anderson museum, and the scientific method of the study was based on describtion, analysis and comparison .

Keywords :Jewelry-turkey- arts- anklets .

عُرفت الحُلى منذ زمن بعيد على مر العصور وذكر فَى القرآن الكريم "وَهُوَ الََّّبي سَخَّرَ الْبَحْرَ

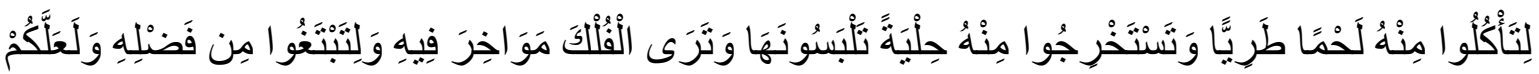

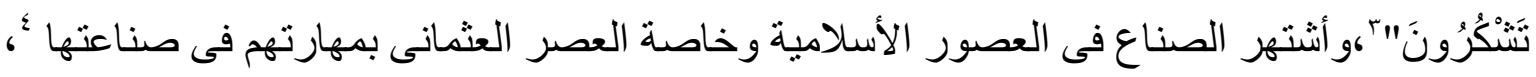
وكان للمر أه أهتمام فطرى بزينتها لأبر از جمالها منذ أن وجدت على الأرض فعلى مر العصور أعتادت المر أه على التزيين وليس فقط لتظهر أكثر فتنة و إنما كانت تريد الز هو والتعالى على الآخريين ؛ ، حتى النساء الفقير ات حاولو تقليد نساء الطبقات العُليا لكن بخامات أقل قيمة وبأثمان زهيدة ، ثم أصبحت تر غب فى البساطة التى لا تخلو من سمات الأناقة و الجمال '. لم يتغير شغف النساء بالحلى فى عصر من العصور إلا فى أختلاف الأنواع وطرق الصناعه وكانت الحلى هو الدليل على مدى ثراء العصر ، وقد كانت النساء المصريات فى العصر العثمانى على أختلاف طبقاتهن تهنم باقتناء الحلى حتى نساء الطبقة الدنيا، أما نساء الطبقات العليا كان لهم أهتمام أكبر بأقتناء المجوهرات حيث أن الحلى للمر أه لم يكن للزينة فقط بل أصبح بمثابة خز انة جيدة لأمو ال الرجال وخاصة فى فترة عدم الأستقرار السياسى ، فكان يضع الرجل جزء من ثروتة فى حلى زوجته وقد سجل وورد فى المصادر التاريخية تفاصيل ماصادره العثمانيون من حُلى لزوجة السلطان طومان باى بعد أن هربت جاريتها الجركسية عند أحد الوزر اء العثمانين ودلتهم على مكان خزنتها ، وعلى 
هذا فبالرغم من ظروف الأوضاع الأقتصادية فى العصر العثمانى حرصت المر أه فى هذة الفترة

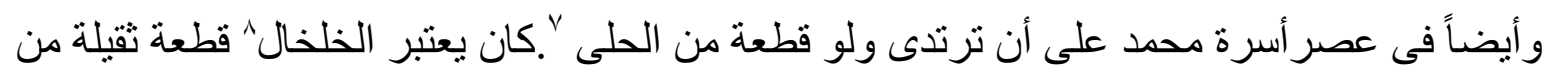

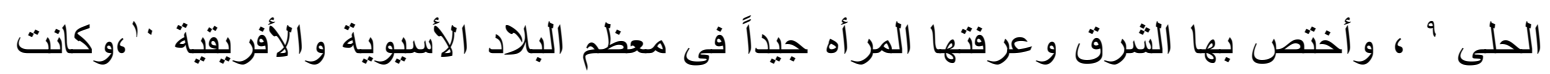
تحدث رنيناً عند أحتكاك الخلخال بالأخر فيلفت أنظار الرجال و العقول حنى نظمت كلمات تتغنى برنة

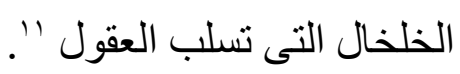
وأحياناً كان يثبت بالخلخال بعض الجلاجل التى تحدث رنيناً ب' أحيانا يكون من سلسلة تحيط بأسفل

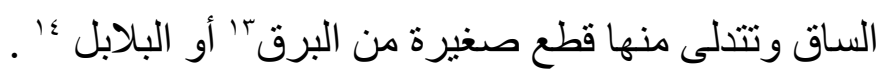

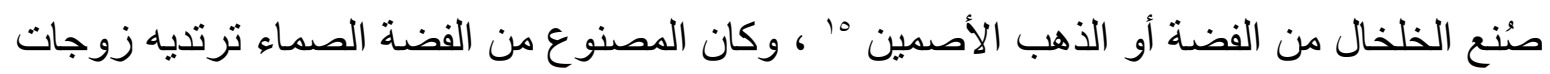

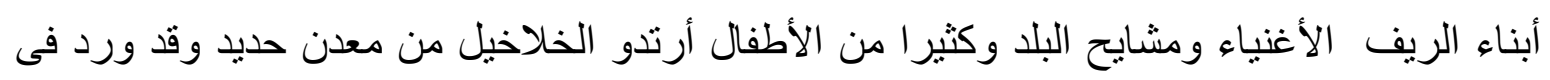

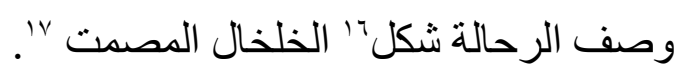

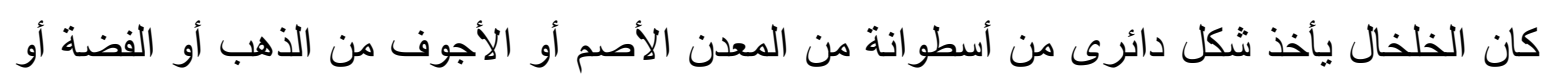

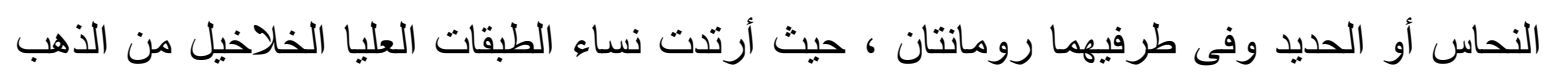

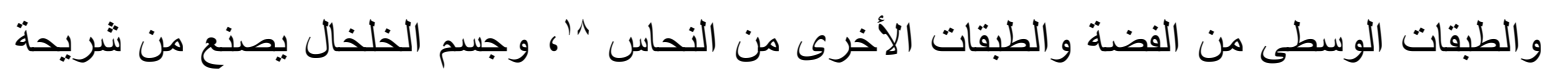

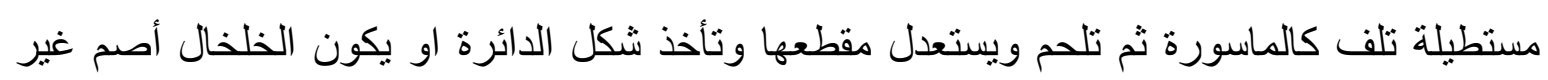
مجوف و هذا النوع كان الطلب علية أكثر من النوع الأجوف لأنه أثقل كثير اويحتوى على كمية كبيرة

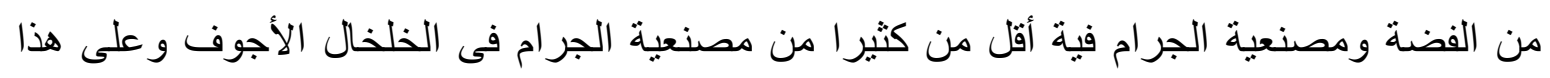

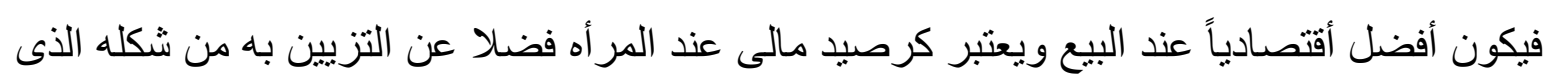

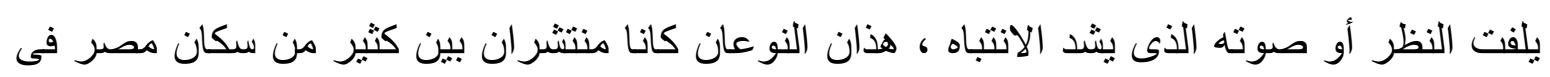

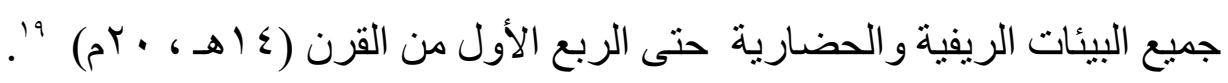

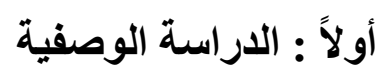

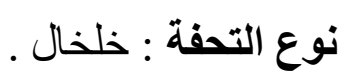

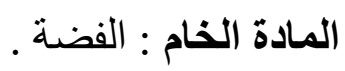
مكان الحفظ : متحف جاير أندرسون .

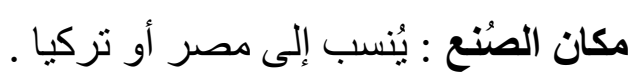

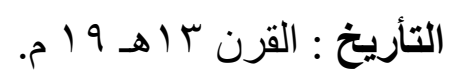
الأساليب الزخرفية : التطعيم بالمينا . التمارئ العناصر الزخرفية : زخارف نباتية 
المقاييس :• (. طول

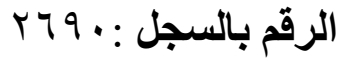

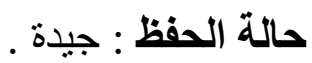

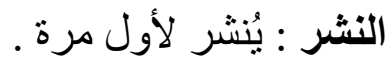

الوصف : خلخال من الفضة على شكل دائرى كامل و ملتوى على بعضه، ينتهى طرفى الخلخال

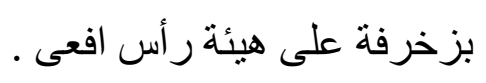

الخلخال من الداخل خالى من الزخرفة اما بدن الخلخال من الخارج علية زخارف نباتية من وريدات صغيرة وزهرة اللوتس يحيط بهم بعض الأثكال المجردة ويملىء الفراغات أثكال تتخذ هيئة قنشور

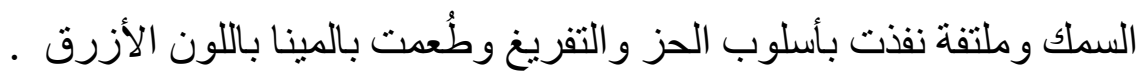

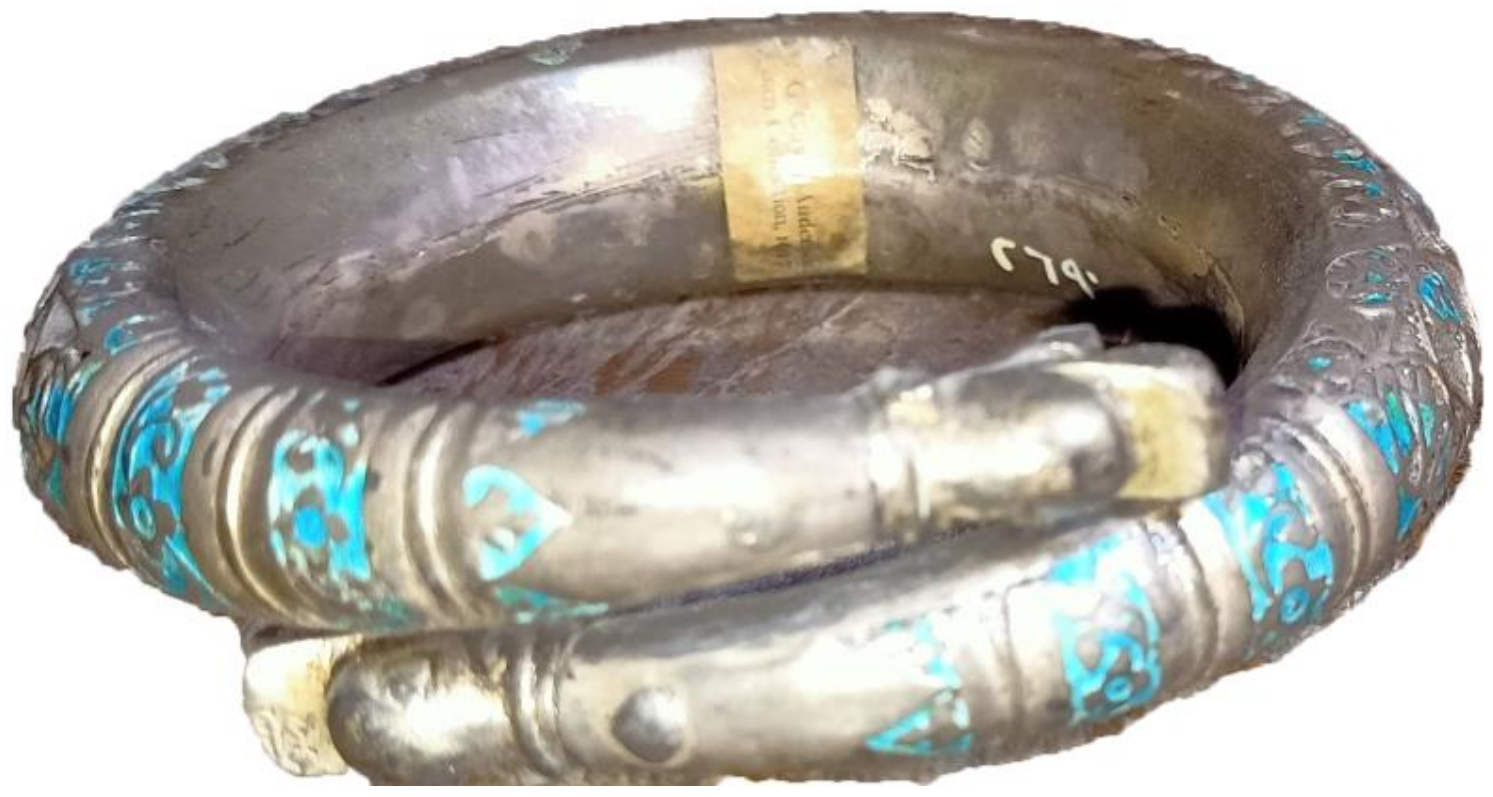

لوحة ( ) خلخال من الفضة ، محفوظ بمتحف جاير أندرسون ، يُنسب إلى مصر أو تركيا ، القرن با

$$
\text { هـ }
$$




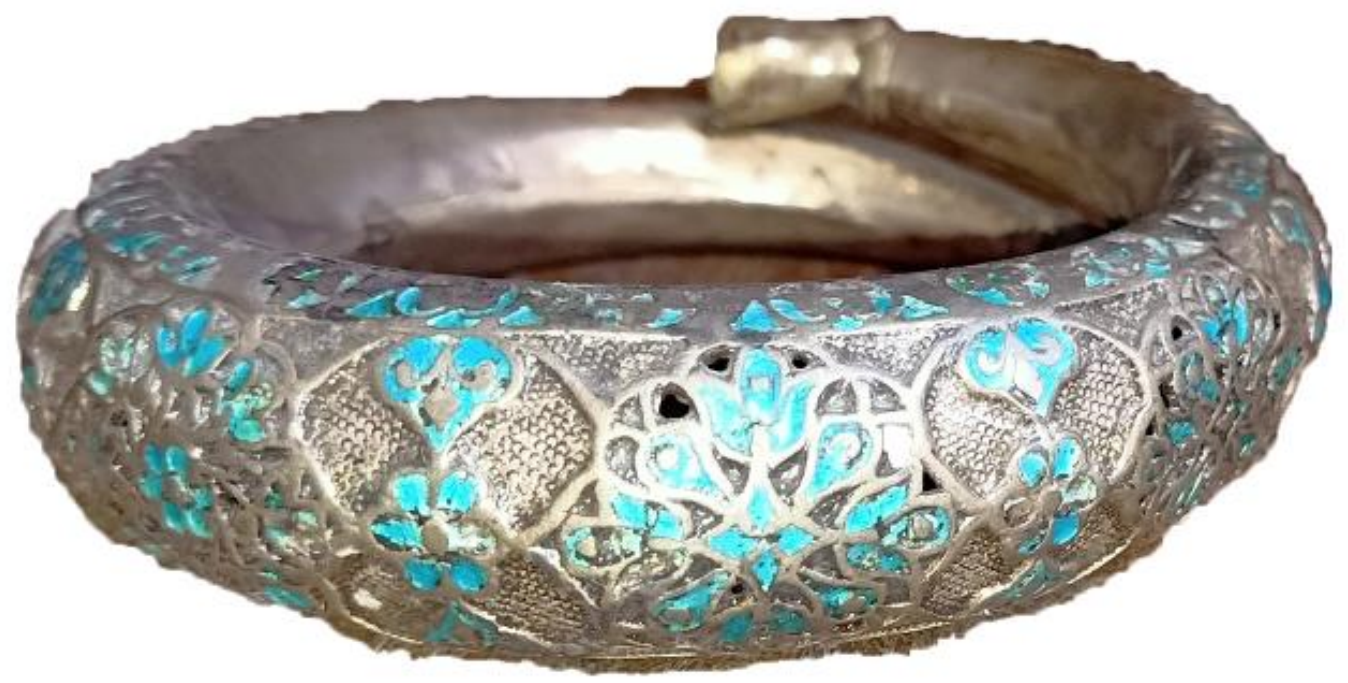

تفاصيل زخرفة من اللوحة السابقة ، توضح أنو اع الزخارف النباتية المطعمة بالمينا فى بدن الخلخال. ثانياً : الدراسة التحليلية لعبت المعادن دوراً هاماً فى صناعة الحُلى على مر العصور ، وقد أضافت القاهرة فى العصر

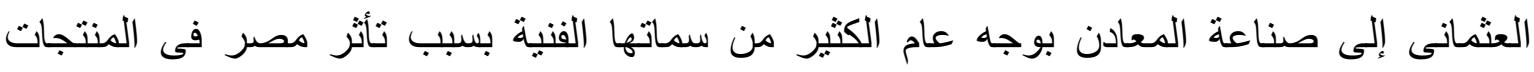

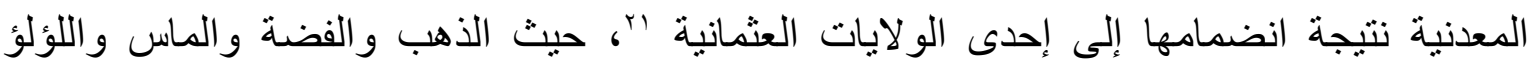
و غيرهم ، كان أنقاهم الذهب حيث لايتأكسد ولا ينأثر بالأحماض والعواتهات العل الجوية ويلية مباثرة الفضة

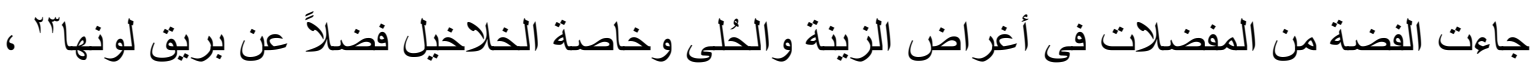

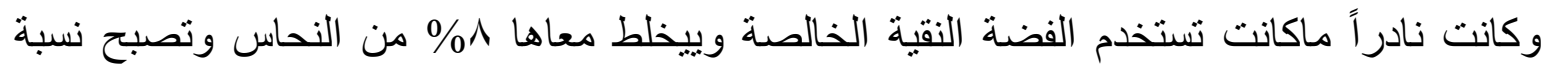

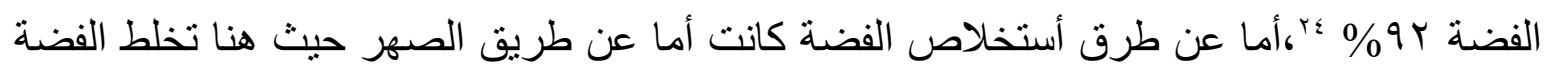
بخامات رصاص ونحاس وتصهر معاً. . ويمتاز معدن الفضة بقابليته للطرق و التشكيل أكثر من الذهب وقابليتها للسحب حيث ليونتها وقابليتها

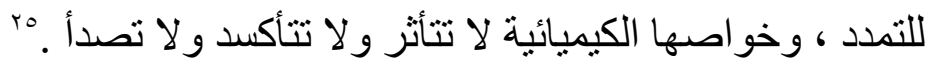

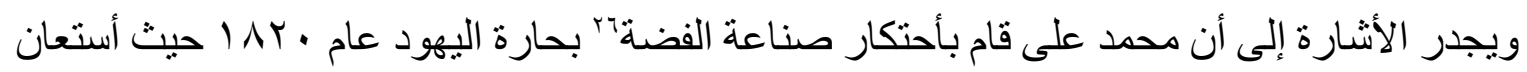

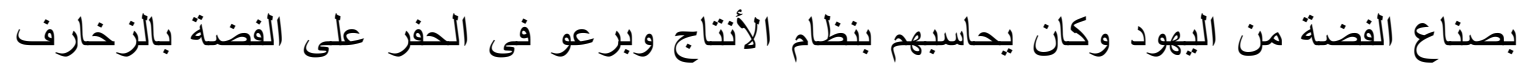
النباتية rv 
الأساليب الصناعية وطرق التثكيل التى أستخدمت للقطعة محل الاراسة : الصب فى القالب : حيث أن الفضة من المعادة سهلة الانصهار فأستخدمت هذة الطريقة فى الخلخال حيث يتكون القالب من جزأين موجب وسالب وينقش من الداخل بالحفر الغائر لأستخر اجز زخارف منقوشة وبارزة ثم يترك لييرد وتأتى عملية فلك القالب و الصنفرة والتلميع للتحفة الفنية ^^،تعتبر من أفضل الطرق حيث يمكن التشكيل من خلالها بزخارف بالغة التعقبد كالأشكال المغلقة ومتعددة الزوايا

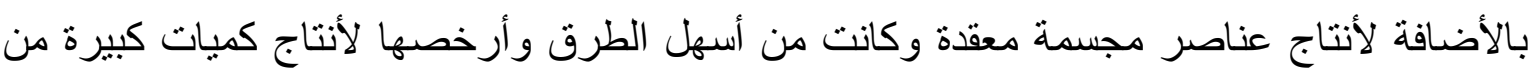

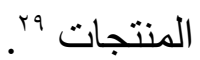

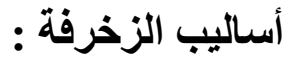
طريقة الحز : تقوم هذة الطريقة بأجراء حزوز أو نقوش غير عميقة على سطح المعدن بواسطة أدوات

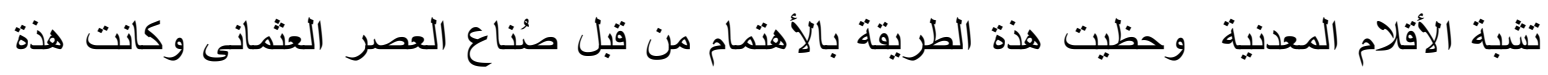
الطريقة أضافة لدظهر التجسيم للعناصر الزخرفية النباتية بتزويدها خطوط قصيرة ودقيقة لr.

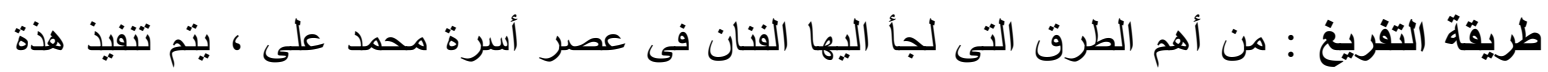

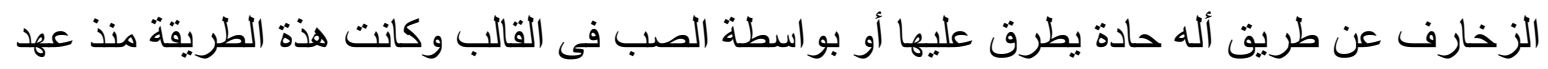

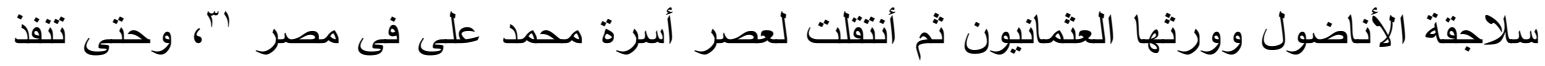

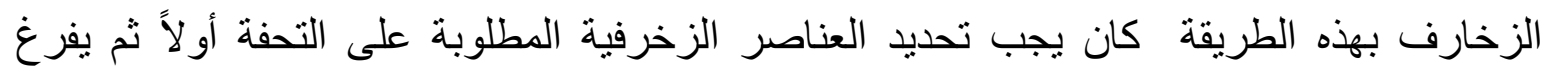

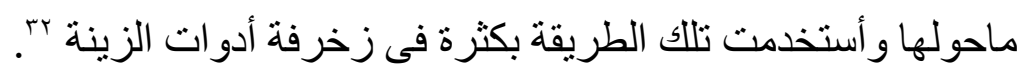
طريقة التطعيم بالمينا : فن الزخرفة بالمينا كان من أكثر الفنون الممتعة للفنان ، وأختلفت الأراء فى لهى

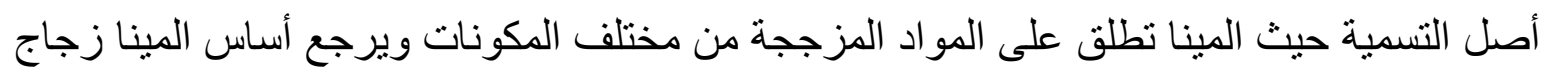

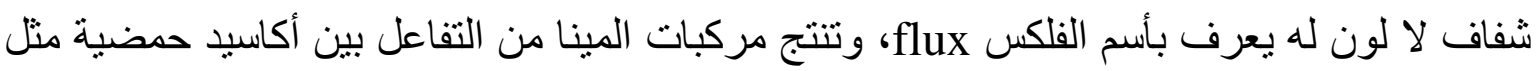

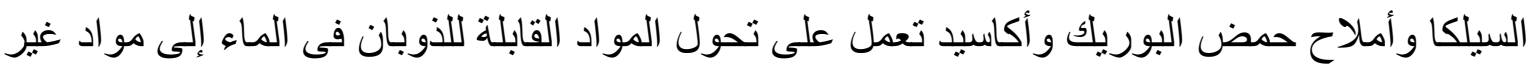

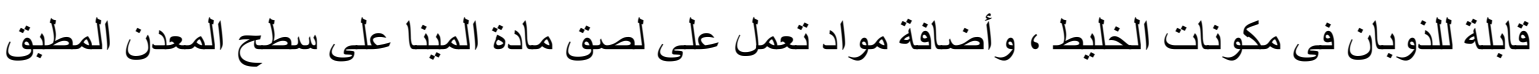

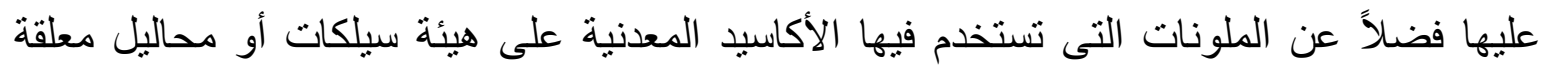

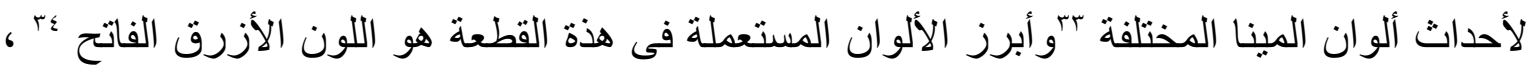

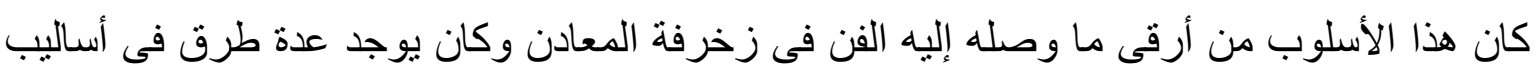

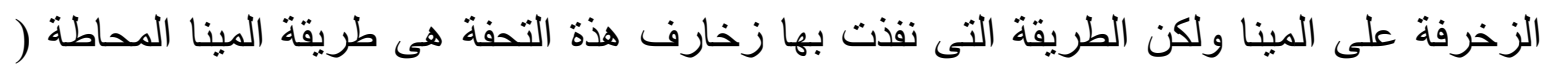


استخدمت هذة الطريقة على التحف الفنية ذات المشغولات الدقيقة كالحُلى ، تطبق المينا الملونة منفصله عن بعضها داخل فو اصل حددت بأسلاك رفيعة من الفضة ، وتشكل هذة الأسلاك الرفيعة وفقاً للتصميم المطلوب ، ثم ثتبت بمواد سريعة الألتصاق ، يراعى وضع المينا داخل الخانات المحددة ثم يضغط عليها فى كل خانة للتخلص من الفراغات ثم تجفف المينا إذا كانت رطبة قبل صهر ها، نفذت هذة الطريقة على البدن الخارجى للخلخال المزين بالزخارف النباتيةهr .

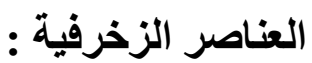

أولاً الزخارف النباتية : زخرفت قطعة الخلخال بزخارف من أثكال الوريدات الخماسية وأثنال محورة حيث ملء الفر اغات وتماثل العناصرو أيضاً زهرة اللوتس. زهرة اللوتس بّ": أقتبست هذة الزهرة عن الصين فى عهد أسرة تانج فكانت ترمز عندهم إلى أنبثاق الحياة ثم أنتشرت إلى الغرب على يد المغول لمدة قرنين، و أنتشرت إلى العالم الأسلامى حتى أصبحت من العناصر الزخرفية الهامة لكافة الفنون والجدير بالذكر أن أستخدام زهرة اللوتس بَّ، فى المشرق الأسلامى وفق الأسلوب الصينى وليس الاسلوب المصرى^^ فى الحضارة المصرية

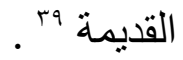
ثنانياً: الأشكال الحيوانية : ظهرت شكل الأفعى على طرفى الخلخال ، فكانت الأفعى فى القديم رمزاً للخلود لما أعتقده القدماء من قدرتها على الفرار من الموت وتغير جلدها وأيضاً من بعض التفسيرات أعتبار ها كطلسم للحماية من شر الأفات والزواحف ،وقد ظهر هذا الثكل على رسوم المعادن العثمانية بشكل خر افى وهى من

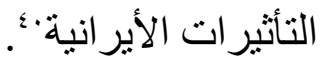
ظهر أيضاً زخرفة قشور السمك هى نوع من الأشكال الهندية المستوحاه من أجزاء من كائنات حية و هى الأسماك ، هى من التأثثرات الساسانية المعروفة وقد ظهرت فى الفنون الأسلامية على الخزف الفاطمى والسلجوقى و على الخزف المملوكى "؛، وتعتبر من العناصر الزخرفية التى أستخدمها الفنان العثمانى ونسبت خطأ إلى رودس وفى الأصل ،ويتخللها الأفرع النباتية זهو الوريدات كما هو موضح بالتحفة . 


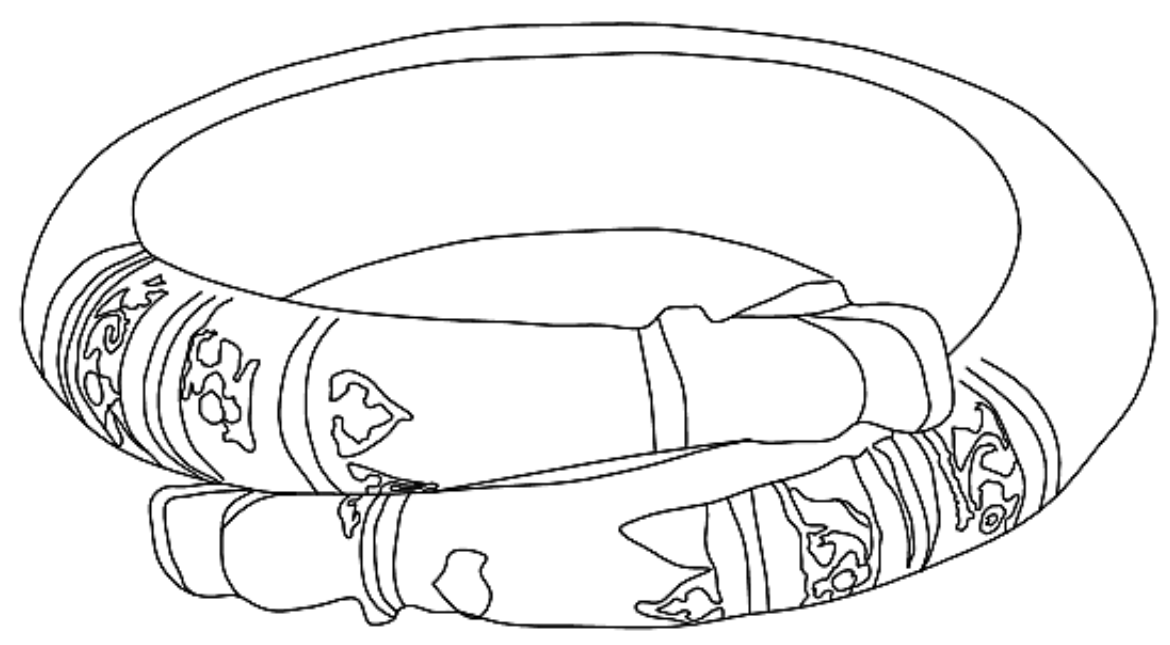

شكل ( (1) يوضح الثكل العام للخلخال يوضح شكل رأس الأفعى على طرفى الخلخال. عمل الباحثة.

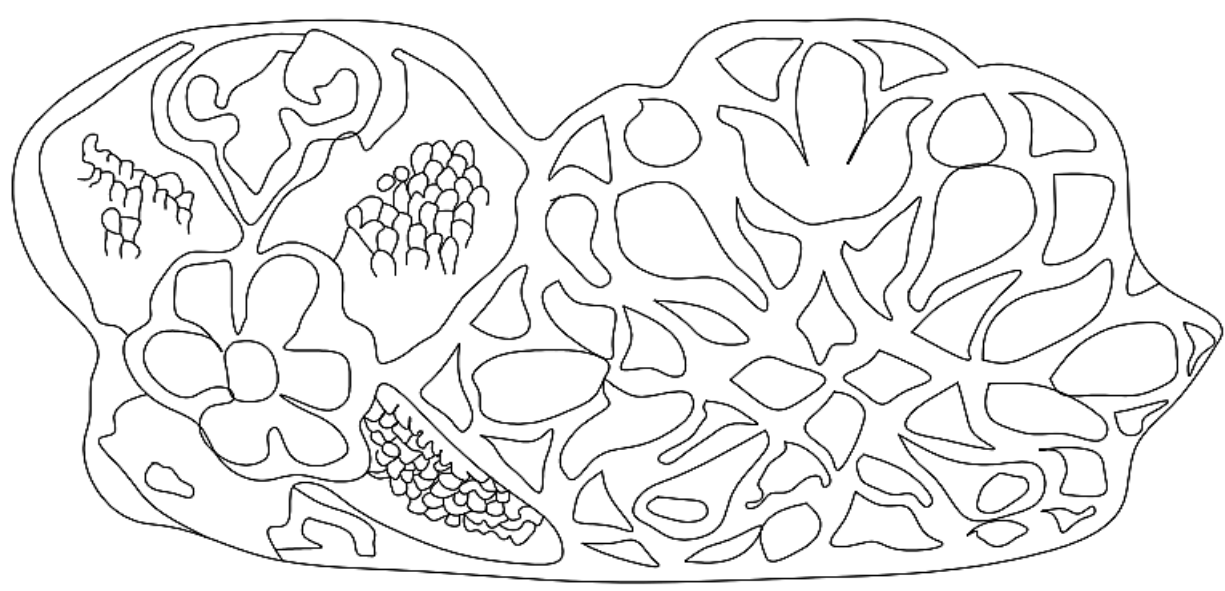

شكل( ا ـأ ) نموذج يوضح شكل الزخارف على البدن الخارجى للخلخال من قشور السمك وزهرة اللوتس. عمل الباحثة 


$$
0
$$




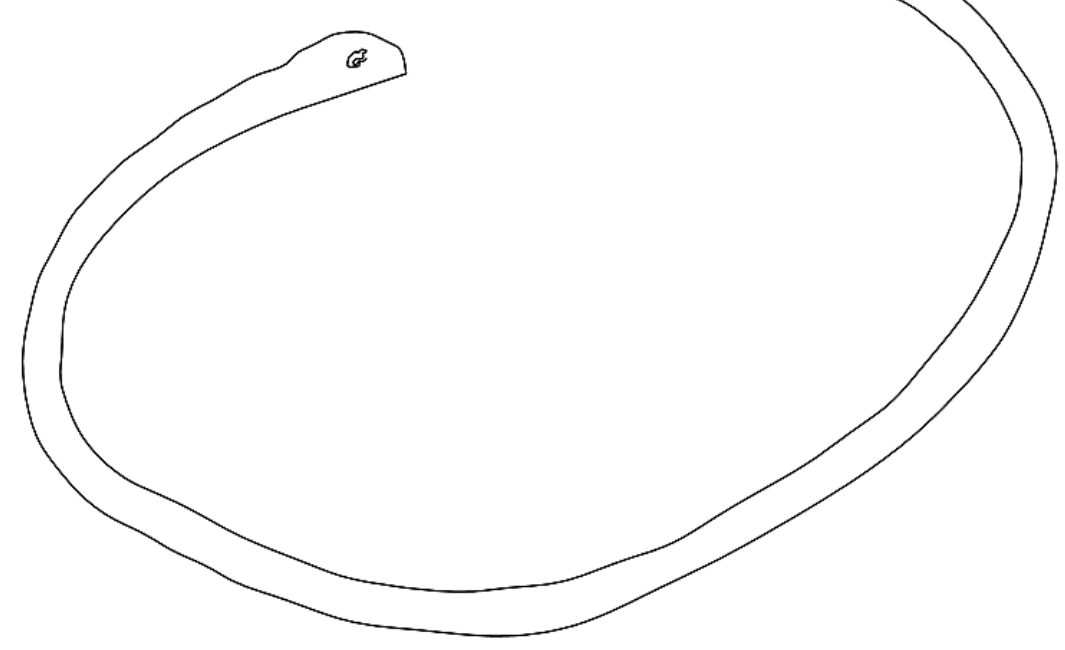

شكل (؟ -أ) يوضح الثكل العام للخلخال وزخرفة ر أس الثعبان على طرفى الخلخال . عمل الباحثة 
مما سبق نستخلص بأنة أثمرت در اسة قطع الحلى من معدن الفضة بعض النتائج على النحو التالى : هذة التحفة صُنعت من معدن الفضة ويتميز بخاصية الأندماج مع كافة المعادن الفلزية وبالتحديد تللك التى تستعمل فى صناعة الحلى . تتطابق شكل التحفة المستدير مع الغرض الجمالى فى زينة الأقدام الذى صنعت من أجله و على سبيل المثال : أستخدام طريقة الصب فى القالب فى تشكيل الهيكل الخارجى للخلخال. الأبداع فى شكل العناصر الزخرفية بطريقة الحز والتفريغ واستخدام اسلوب التطعيم بالمينا الزرقاء اللون . 
'- 'ـ استاذ الفنون الأسلامية ورئيس قسم الآثار الأسبق بكلية الاثار - جامعة القاهرة .

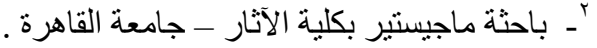

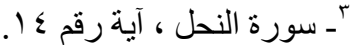

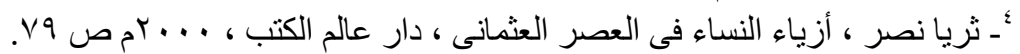

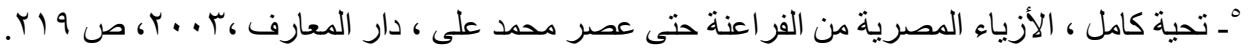

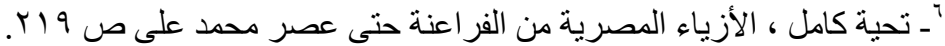

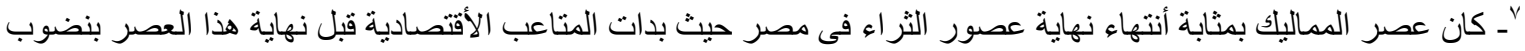

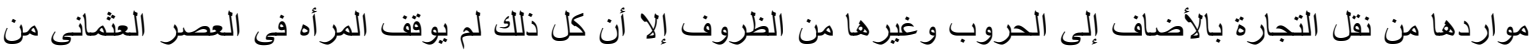

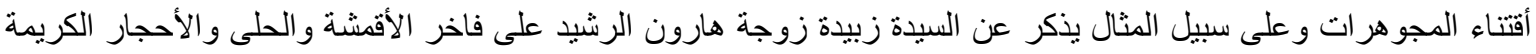

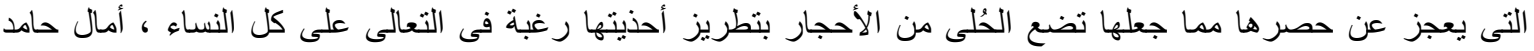

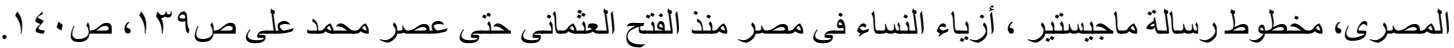

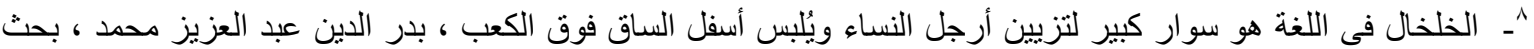

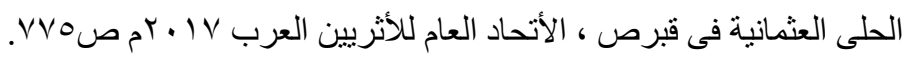

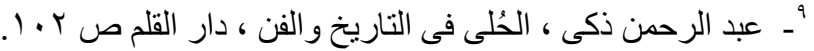

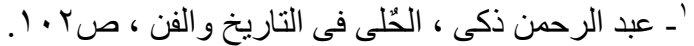

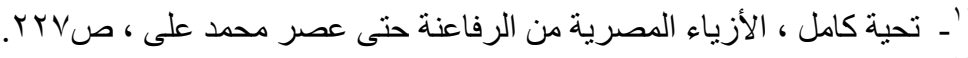

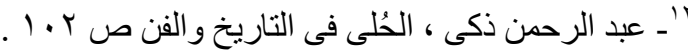

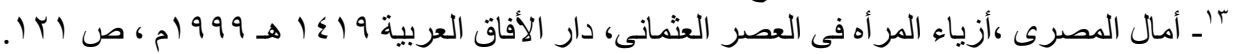

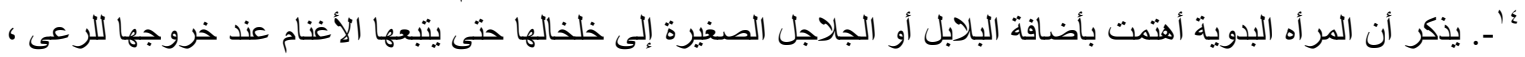

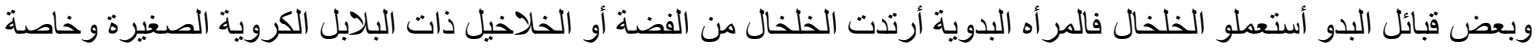

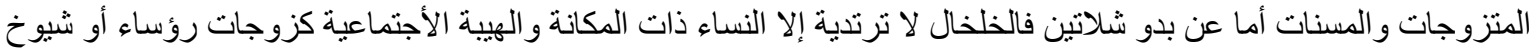

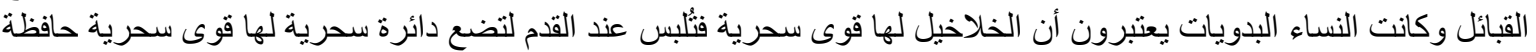

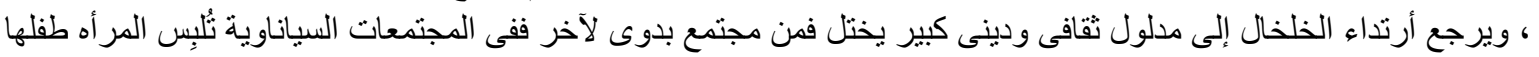

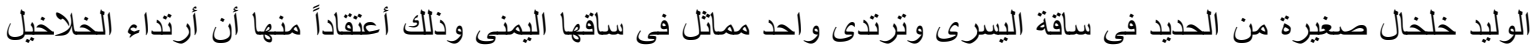

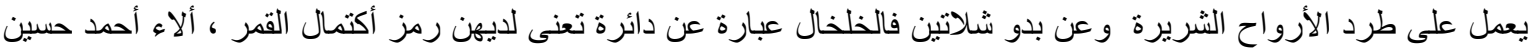

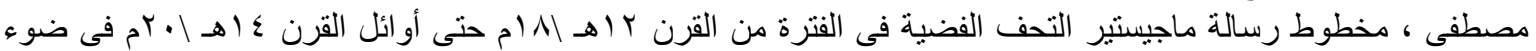

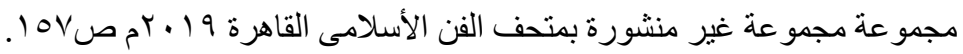

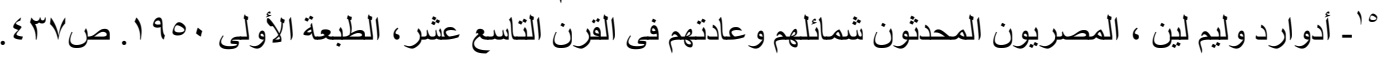

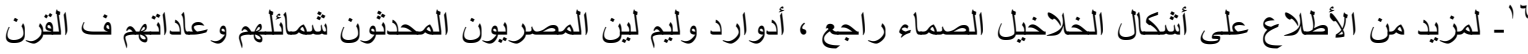

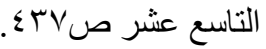

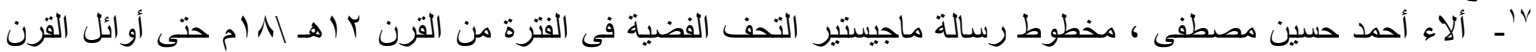

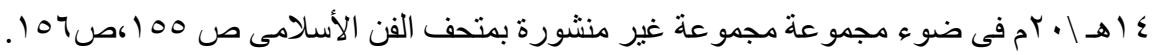

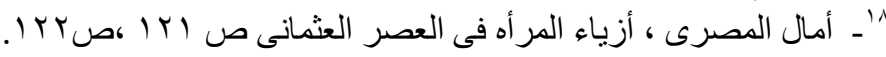

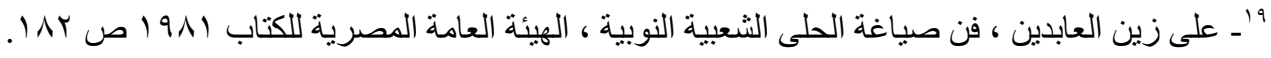

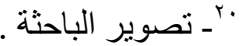

"Oktay aslanapa,Turkish art and arcthitectureK praeger puplishersK new york washington .p.80. r بـ كانت الفضة من أثهر المعادن فى اليمن وكانت جزيرة العرب من جملة الأسواق التى مونت العبرانيين وكان الكمبائيون

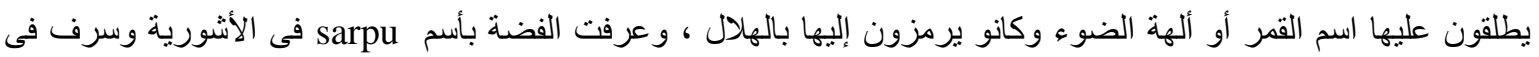

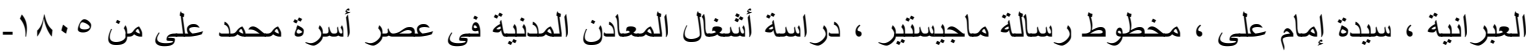

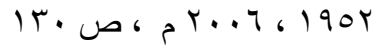

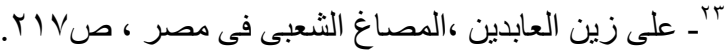

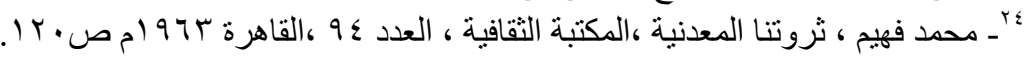




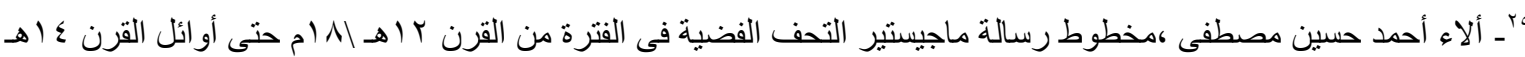

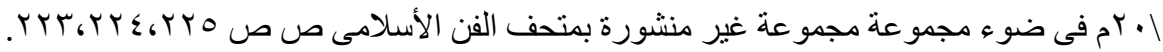

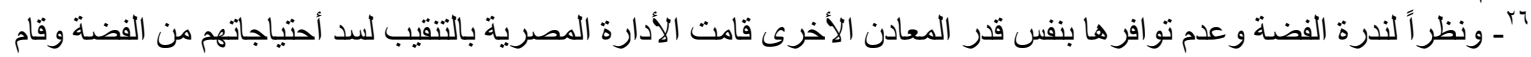

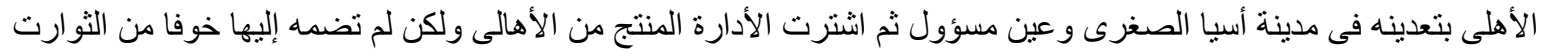

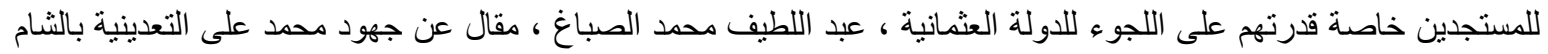

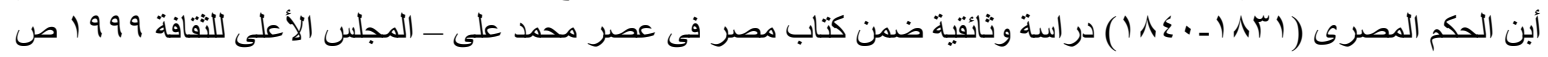

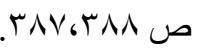

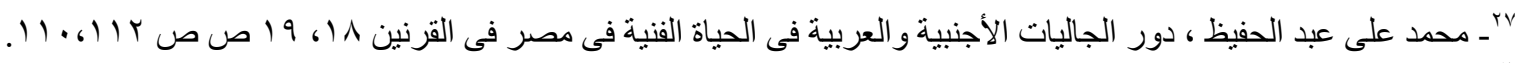

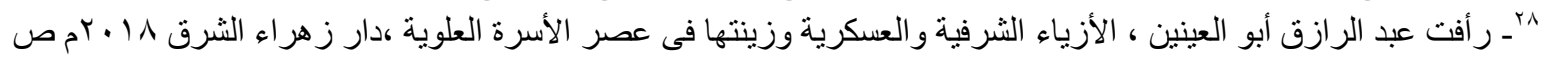

TrA

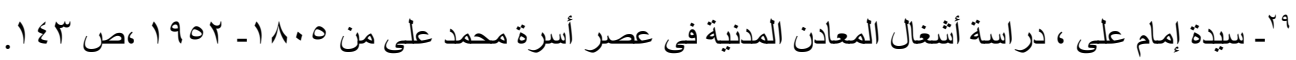

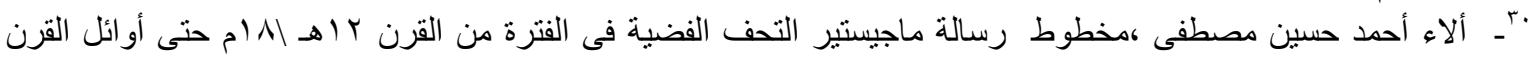

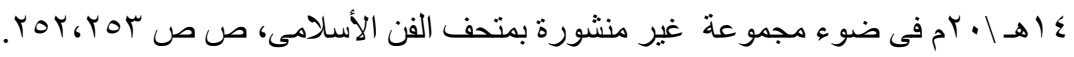

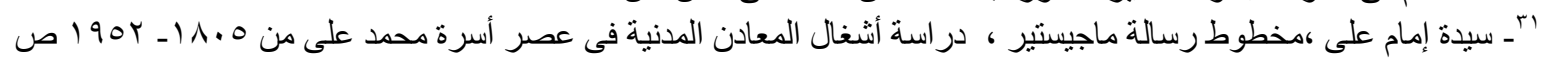

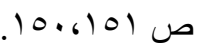

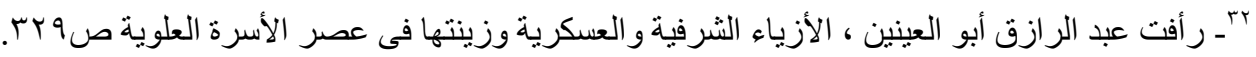

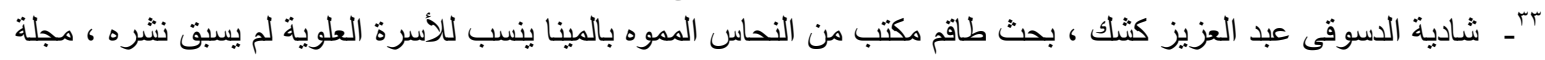

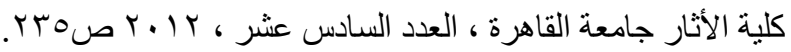

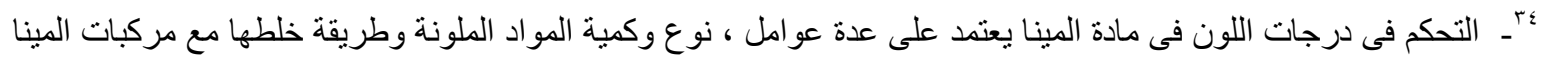

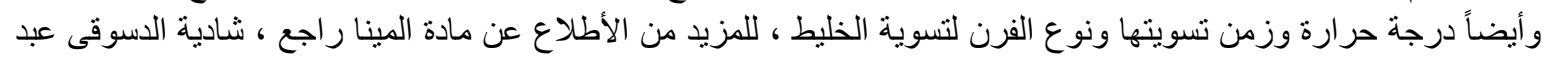

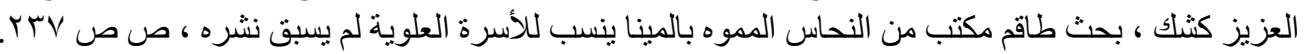

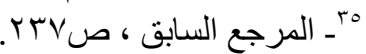

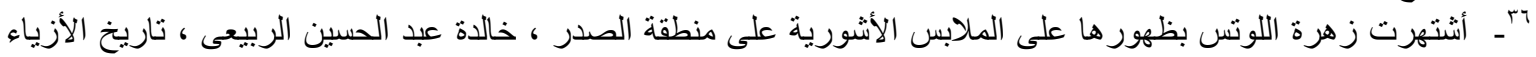

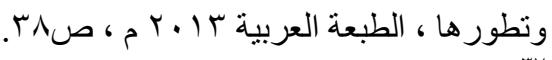

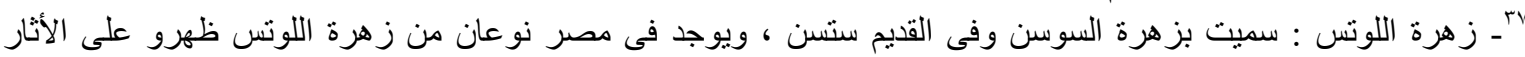

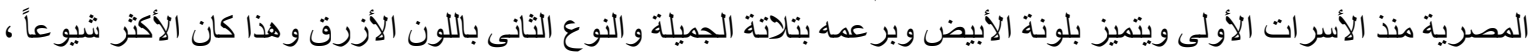

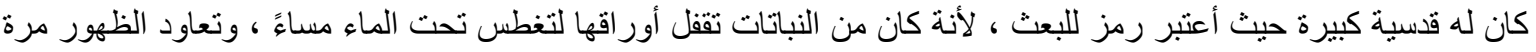

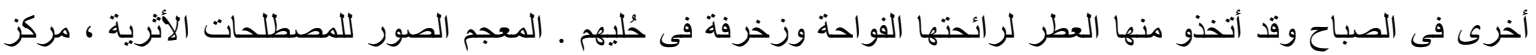

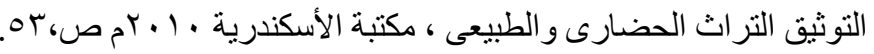

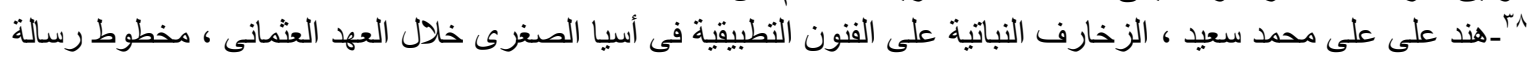

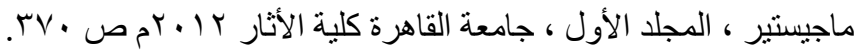

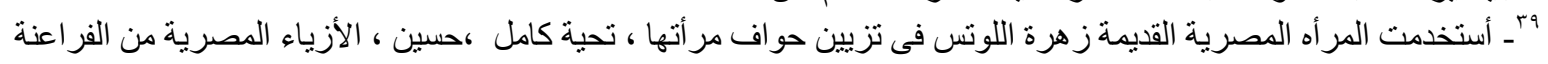

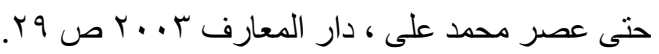

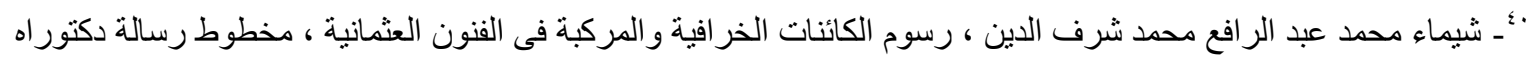

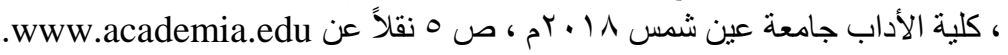
اء ـ ولاء جلال سالم موسى ، الأدوات المنزلية المعدنية فى عصر أسرة محمد على ، مخطوط رسالة ماجيستير ، كلية الآثار ،

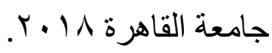

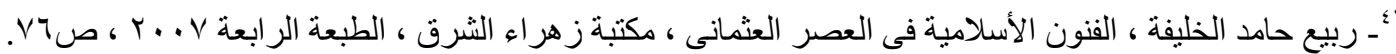

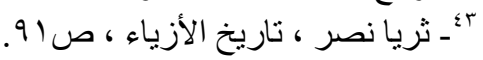

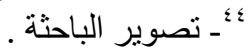

